\title{
Expressive Arts Activities as Tools to Enhance the Education of Clinical Psychologists: A Qualitative Study
}

\author{
Rosangela Bertelli \\ Universidade de Trás-os-Montes e Alto Douro \\ Escola de Ciências Humanas e Sociais \\ Quinta de Prados, 5001-801 \\ Vila Real, Portugal
}

\begin{abstract}
Educating clinical psychologists through the use of expressive arts activities allows the novices to become aware of those cognitions that flow without their conscious control, and educating cognitive-behavioural clinical psychologists through the use of expressive arts activities allows the novices to grasp how the four elements (circumstances, cognitions, emotions, and behaviours) of the cognitive-behavioural model of learning are all entwined. Such understanding is central to the ability to recognise maladaptive or dysfunctional symptoms. The research problem here was: Would the novices remain on the expressive art activity just observing their own flow of automatic cognitions, without complying with those thoughts and associated emotional reactions? Eighteen female graduate students were being educated through the use of expressive arts activities in order to comprehend the cognitive-behavioural psychotherapies. Qualitative data obtained through descriptive written reports made by the students themselves were triangulated and data analysis shaped the scenario that the expressive arts activities facilitate the development of an attentive awareness that allows for the witnessing of one's streams of thoughts and associated emotions. Expressive arts activities do add something extra that make the learning process more intense, better, more captivating, and tangible to the novices.
\end{abstract}

Keywords: Attentive Awareness, Automatic Thoughts, Cognitive-Behavioural Clinical Psychologist, Expressive Arts

\section{INTRODUCTION}

Art can be defined as the "human ability to put an idea into practice" [1] and a recent article just published in Nature [2] revealed that our ancestors during the Pleistocene already produced art, cave art, by means of the depiction of figures of humans, wild cattle, boats, geometric designs, and hand stencils, plus Schüler, in acquainting the guests at Plato's The Banquet, in particular Socrates, states that "...Art allows us to approach reflexively acts that frighten us..." [3]. What about applying some expressive arts activities in the education of clinical psychologists?

Educating clinical psychologists through the use of expressive arts activities allows the novices to become aware of thoughts flowing automatically, by reflex, without conscious awareness, without volition or conscious control, and allows for the development of the novices' selfawareness and self-disclosure of personal latent cognitive contents $[4,5,6]$.

\section{Expressive arts activities in the education of clinical psychologists}

Applying some expressive arts activities as tools in educating cognitive-behavioural clinical psychologists in particular provides a means whereby the novice develops awareness of his/her surroundings, sensations, and thoughts. In other words, what is accomplished as a 
result of using such tools (expressive arts activities) is exactly what is required from the novice in order for him/her to grasp how circumstances, cognitions, emotions, and behaviours are all entwined, creating connections that fasten these four elements together, that is, circumstances, cognitions, emotions, and behaviours [4, 5].

\section{A model of learning}

According to the cognitive-behavioural model of learning, the connections among circumstances, cognitions, emotions, and behaviours may lead to self-created problems and consequently to dysfunctional ways of thinking that affect the person's feelings and behaviours. Thus, recognising a self-created problem as such, that is awareness of it or getting the essential qualities or characteristics of those automatically flowing thoughts, is vital to the psychotherapeutic process of resolution of maladaptive or dysfunctional symptoms [7]. In the same way, if the person does not recognise a true problem in respect to its inherent nature, that is, consistent with fact or reality, he/she will miss the opportunity to learn the ability to apply knowledge, experience, understanding or common sense and insight in order to deal with reality.

\section{Thoughts flowing automatically}

Becoming aware of one's own automatic thoughts and repetitive thought patterns is extremely important in the process of getting to know one self, because it is known that most people tend to be identified with those thoughts, mainly with continuous negative and very unfavourable to life automatic thoughts. In other words, one accepts as true his/her automatic cognitions and as a consequence derives the sense of who he/she is from those automatically flowing thoughts conditioned by their past experiences, that is, from their schemata [5].

Dysfunctional cognitive schemata, that is, negative beliefs that are shaped from one's results with initial life's negative experiences, contain an interconnected network of nonadaptive beliefs, emotions, and memories that may be reactivated during adulthood by negative life events [8], and such a network builds a closed circuit of automatic thoughts, emotions, and behaviours that circumscribes and commands, dominates one's mental life.

\section{Watching one's own thoughts}

The practice of expressive arts activities in the process of educating clinical psychologists has the benefit of pre-empting unforeseen difficultness and corresponding emotional reactions during training once expressive arts activities tend to aid or promote at least some well-being $[4,5,6]$. Conscious attention on the expressive art activity in progress heightens the probability of noticing the flows of thoughts without deviating from the activity and without emotionally reacting to the pouring of thoughts, thus allowing the novice to just watch, follow, be vigilant, be on the lookout of his/her own automatic cognitions. The practice of expressive arts activities in the process of educating psychologists matches the practice of accessing one's personal beliefs or judgments that is not necessarily founded on proof or certainty [9].

\section{The purpose of the present article}

The aim of the present article is to describe the process of educating cognitive-behavioural clinical psychologists through the use of expressive arts activities as a focal point, as the concentration point of attention in order to become able to just observe one's thoughts, allowing the flow of automatic thoughts and just watching while thoughts flow, without interfering, letting automatic thoughts come and go, just becoming aware of those automatic thoughts as such. In this manner, expressive arts activities were implemented to allow the novice to enter or to assume a certain state or condition which would provide some comfort and easy in the process of witnessing one's own thoughts. 
Would the novices remain on the activities just observing, witnessing their own flow of thoughts, becoming aware of those thoughts and associated emotions and still keep themselves as just observers of themselves?

\section{Participants}

\section{METHOD}

Eighteen female graduate students, between 21 and 33 years of age, took part in the process of education of cognitive-behavioural clinical psychologists through the use of expressive arts activities. These graduate students were attending a discipline on cognitive-behavioural psychotherapies in a public university. The discipline, which lasted for 20 sessions of two hours each, was part of the curricula for their education and graduation on clinical psychology.

\section{Materials and procedure}

This kind of education requires first and foremost that the novice grasps the cognitivebehavioural model of learning. In order to develop this kind of understanding novices study the model step by step through words, images, and feelings in a journey or route all the way around the concepts of circumstances, cognitions, feelings, and behaviours. Then the novice contemplates those constructs and the relationships among them, and then the novice begins exercising or experiencing firsthand the flowing of his/her own automatic thoughts, getting into contact with some personal latent cognitive contents, and acknowledging it as such.

As thinking just happens, novices do begin noticing or experiencing their own flow of thoughts during the first levels of education, that is, the study and contemplating phases. Afterwards, they are ready to directly experience special sets of circumstances whereas they do not have to occupy themselves with concepts, but just silently focus their senses on the specific circumstances (expressive arts activities) and notice, try to get into their consciousness or be cognitively alert and aware of themselves, aware of the thoughts that happen to flow in the background while they are involved in those circumstances (expressive arts activities).

Expressive arts activities were thus employed as circumstances that would potentially trigger thought processes and emotions and at the same time bring forth or yield a contented state of being happy and capable of discovering, finding out or getting to know about oneself $[4,5,6,9]$.

\section{The expressive arts activities - the last four training sessions}

As mentioned above, novices first study and contemplate the cognitive-behavioural model of learning and when ready they enter the phase of systematic direct experience, that is, practicing awareness or the consciousness of flowing cognition, and acknowledging it as such.

For each and every training session, graduate novices were instructed to execute the activity and simultaneously paying close attention, being aware, watching the automatic thoughts flowing and the associated emotions without becoming involved with those thoughts and emotions, without reacting to them, without being a part of those thoughts and feelings. They were instructed to watch their thoughts while keeping themselves on the task, allowing the thoughts to just flow, just come and leave, passing through. They were asked to just witness the thoughts and emotions, merely letting thoughts and emotions be.

\section{Last but four Sessions}

The novices were provided with a white sheet of lined paper (containing a small origami boat attached to the upper left side of the paper), pen, pencil, eraser, and were asked to consider the question "If I were a boat, what kind of a boat would I be?" 


\section{Last but three Sessions}

The novices were provided with a black sheet of unlined paper, colouring pencils, crayons, were asked to consider the statement "If I were a boat, I would be a boat without a harbour!", and were asked to depict their view on the subject on the surface of the paper provided.

\section{Last but one Session}

The novices were provided with a white paper cylinder, colouring pencils, crayons, were read a La Fontaine Fable, and were asked to depict it on the surface of the white paper cylinder provided.

\section{Last Session}

The novices were provided with colouring pencils, crayons, and a A4 sized photo of an adorable and looking joyful five-year-old child, were told a little bit about the child's life, and were asked to depict, in the back of the photo, the way they mentally perceived the concept of "expecting the best in all things".

\section{Written individual reports}

For each and every session, the novices, after finishing that particular session of expressive arts activity, prepared an Individual Written Daily Reflective Report and then were also invited to share with the group their mental experience, whatever and whenever they felt comfortable sharing it. They also prepared Individual Written Weekly Reflective Reports that were submitted through electronic e-mail.

\section{Results}

Data obtained from the last four sessions were triangulated, that is, data collected from differing sources during those sessions (Written Daily Reflective Report and Written Weekly Reflective Reports) were compared, grouped, and examined in terms of worthy and faults in order to give priority to those findings most relevant to the aim of the triangulation $[4,5,6]$ and any trends in the data. Qualitative data were considered in detail and subjected to an analysis in order to discover essential features of the mental experience described by the novices.

Would the novices remain on the activities just observing, witnessing their own flow of thoughts, becoming aware of those thoughts and associated emotions and still keep themselves as just observers of themselves?

\section{The outgrowth of awareness}

After completing data analysis a theory sprang up, just came into existence, took on a form, and took a shape: Applying expressive arts activities in the education of clinical psychologists facilitate the novices learning of attentive awareness that allows for the observing, the witnessing of one's streams of thoughts and associated emotions.

Novices were able to remain on the activities, expressive arts activities, witnessing automatic thoughts as thoughts flowed and also witnessing associated emotions, and still holding on as just observers of such inner goings. The essential features of the mental experience described by the novices unveiled that expressive arts activities enhance the education of clinical psychologists, in particular cognitive-behavioural clinical psychologists. The use of expressive arts activities as an instrument in the process of educating cognitive-behavioural clinical psychologists add something extra that make the learning process more intense, better, more captivating, and tangible. 
Graduate students reported identification of some unexpected dysfunctional thoughts and some feelings that they watched quietly, just becoming aware of those thoughts or emotions, just observing themselves. For instance: "...I have faced many difficulties in my life..."; “...One day my granddad will die..."; “...My dad's health is getting worse..."; “...I am tired of pretending to be strong..."; "...I am ignorant..."; “...I am lazy..."; “...I do not know anymore anything about what I learned in school..."; "...I do not have many friends..."; “...shame, helplessness..."; “...In real life it is not all that easy..."; "...I need to find myself..."; "... When I think that I am unable, I make excuses not to feel so bad..."; “...I miss being happy without knowing...”. They also reported noticing some adaptive thoughts followed by pleasant emotions, for instance: "...I would like to share my experience here with everyone..."; "...Indeed the emotions we feel have nothing to do with the circumstances themselves, but have everything to do with the way we see the circumstance..."; "...Let us stay in this activity just a little bit longer..."; "...This activity filled my heart with love..."; "...I felt cheerful and filled with a feeling of peace..."; "...Many automatic thoughts passed, yet I felt so calm, relaxed..." Some reported being involved in some operant behaviours as a result of pleasurable sense perception, for instance: “...I liked the texture of that piece of paper..."; “...there came a time when I was painting random clouds, just because I was enjoying the way the pencil matched the sheet, both in colour and texture..."; "...I could not stop touching the small origami boat attached to the sheet of paper..."

\section{DISCUSSION}

Would the novices remain on the activities just observing, witnessing their own flow of thoughts, becoming aware of those thoughts and associated emotions and still keep themselves as just observers of themselves? Results showed that applying expressive arts activities in the education of cognitive-behavioural clinical psychologists operated as appropriate tools for achieving the particular end of being able to stay in the same place or state for a given period of time just witnessing flows of automatic thoughts, and becoming aware of those thoughts and associated emotions. In that sense, expressive arts activities revealed themselves as advantageous tools for the student to stay alert, vigilant, watchful, inspecting her flows of thoughts and feelings without reactivity, without feelings of uneasiness, and still keeping themselves on the task.

Being able to just acknowledge their automatic thoughts and let those thoughts flow allows for twofold: On the one hand, it allows for the required detachment in order to be able to live a non-conceptual learning experience of those cognitive-behavioural concepts and, on the other hand, it allows for the experiencing of bringing some awareness to the thoughts and emotions or, in other words, it allows for the consciousness of inner goings that cannot be named. Being able to just acknowledge one's own thoughts and emotions allows for getting in touch with one's inner speech or descriptive thoughts without judging the thoughts and, as a direct consequence, without emotionally reacting to the thoughts.

Expressive arts activities enhance the education of cognitive-behavioural clinical psychologists, because those activities promote enjoyable circumstances that allow the students to experience or go or live through the elements of the cognitive-behavioural model of learning. Such knowing originates awareness that sees what the mind does (thoughts / emotions / actions / emotions / thoughts) without complying with inner goings, just witnessing the theoretical model inside one's own mind [9].

Having firsthand knowledge of thoughts, situations, sensations, and behaviours begins cultivating one's ability to apply consciousness, attentive awareness, in any situation. Such mental ability appeases negative emotions by one's awareness that those emotions arise from negative thoughts that misinterpret situations and also that one's negative thoughts trigger 
negative emotions. Acknowledging one's automatic thoughts and emotions, staying aware, alert, as just the observer of one's thoughts and emotions requires intentional effort and perseverance and the novices were able to grasp existentially the theoretical model holding the cognitive-behavioural psychotherapies.

\section{CONCLUSION}

Verbalizations are not enough in the process of educating psychologists and expressive arts activities seem to provide the necessary experiencing of certain inner goings.

\section{References}

Houaiss, A., Villar, M. S., \& Franco, F. M. M. (2008). Minidicionário Houaiss da Língua Portuguesa (3ª ed.). Rio de Janeiro: Objetiva. ISBN: 978-85-7302-907-9

Aubert, M., Setiawan, P., Oktaviana, A. A., Brumm, A., Sulistyarto, P. H., Saptomo, E. W., et al. (2018). Palaeolithic cave art in Borneo. Nature. Published online November 7, 2018. DOI: 10.1038/s41586-018-0679-9.

Platão (427-347 a.C.). O Banquete [Plato's The Banquet 427-347 BC]. Translated, annotated, and commentated by Donaldo Schüler. Porto Alegre, RS: L\&PM, 2017, coleção L\&PM POCKET, vol. 711. Bilingual Edition GreekPortuguese. ISBN 978-85-254-1788-6

Bertelli, R. (2017a). The generative process of professional and personal development of cognitive-behavioural clinical psychologists in training through the inclusion of strategies of expressive arts activities: A qualitative analysis and comparison. Journal of Arts \& Humanities, 6(8), 37-46. Retrieved from https://theartsjournal.org/index.php/site/article/view/1244/600

Bertelli, R. (2017b). The effects of expressive arts on the evoking of automatic thoughts during the training at a graduate level of personal and professional development of cognitive-behavioural clinical psychologists: A qualitative study. Review of Arts and Humanities, 6(1), 7-11. Retrieved from http://rahnet.com/journals/rah/Vol_6_No_1_June_2017/2.pdf

Keller-Dupree, E. A., \& Perryman, K. L. (2013). The effects of an expressive arts therapy group on female counsellors-in-training: A qualitative study. Journal of Poetry Therapy, 26(4), 223-235. DOI: 10.1080/08893675.2013.849041

Beck, A. T. (1991). Cognitive therapy and the emotional disorders. London: Penguin. ISBN 10: 0140156895

Clark, D. A., Beck, A. T., \& Alford, B. A. (1999). Scientific foundations of cognitive theory and therapy of depression. Hoboken, NJ: Wiley. ISBN: 978-0-471-18970-1

Carroll, D. (2018). Enhancing cognitive behavioral therapy and expressive arts therapy by applying a hybrid approach. (Expressive Therapies Capstone Theses, 52). Retrieved from https://digitalcommons.lesley.edu/expressive_theses/52/ 